\title{
Genotyping of Chlamydia abortus using multiple loci variable number of tandem repeats analysis technique
}

\author{
Sara Barati ${ }^{1}$, Naghmeh Moori Bakhtiari² ${ }^{*}$, Leili Shokoohizadeh ${ }^{3}$, Masoud Ghorbanpoor ${ }^{2}$ and Hassan Momtaz ${ }^{4}$
}

\begin{abstract}
Background: The correlation between various factors (geographical region, clinical incidence, and host type) and the genomic heterogeneity has been shown in several bacterial strains including Chlamydia abortus.

Methods: The aim of this study was to survey the predominant types of $C$. abortus strains isolated from ruminants in Iran by the multiple loci variable number of tandem repeats (VNTR) analysis (MLVA) method. C. abortus infection was evaluated in a total of 117 aborted fetuses by real-time PCR. The isolation was done via the inoculation of the positive samples in chicken embryo and the L929 cell line. Genotyping was carried out by MLVA typing technique.

Results: Forty samples (34.2\%) were detected with C. abortus infection; however, chlamydial infection in ruminants of Charmahal/Bakhtiari (3 bovines and 35 sheep) was higher than that of Khuzestan (2 sheep). All MLVA types (MT1-MT8) were detected in the collected samples from Charmahal/Bakhtiari but only 2 types (MT1 and MT3) were reported in samples from Khuzestan. The main MT type was MT1 (32\% of aborted fetuses). Although in this study only 9 cow samples were investigated, they possessed similar clusters to those obtained from sheep (MT1 and MT6). Variation of type in sheep samples (MT1 to MT8) was more than that of bovine samples (MT1, and MT6).

Conclusion: By this research revealed that C.abortus was responsible for a significant percentage of ruminant abortion in two studied regions. The main MT type was MT1 (32\% of aborted fetuses) and also 7 different genotypes were involved in infections. So it is concluded that diversity in C.abortus genotyping is high in two regions.
\end{abstract}

Keywords: Chlamydia abortus, Genotyping, Iran, MLVA, Ruminants

\section{Background}

The family of Chlamydiaceae contains obligate intracellular Gram-negative bacteria, with 14 confirmed species (Chlamydia trachomatis, Chlamydia pneumoniae, Chlamydia abortus, Chlamydia caviae, Chlamydia felis, Chlamydia muridarum, Chlamydia pecorum, Chlamydia psittaci, Chlamydia suis, Chlamydia avium, Chlamydia gallinacea, Chlamydia serpentis, Chlamydia buteonis

\footnotetext{
*Correspondence: n.moori@scu.ac.ir

${ }^{2}$ Department of Pathobiology, Faculty of Veterinary Medicine, Shahid Chamran University of Ahvaz, Ahvaz, Iran

Full list of author information is available at the end of the article
}

and Chlamydia poikilothermis) and 4 candidate species (Chlamydia ibidis, Chlamydia corallus, Chlamydia sanzinia and Chlamydia testudinis) related to a single genus of Chlamydia [1-3].

C. abortus is the most common cause of infectious abortion in sheep and goats in many countries in the world. Also, it recognized as causative agent of a various diseases, including fertility disorder, conjunctivitis, arthritis, mastitis, and pulmonary inflammation (endemic among small ruminants) [4-7]. No clinical signs are observed in the pregnant animals prior to the abortion (in last 2-3weeks of gestation) or the delivery of very weak lambs. Moreover, the disease affects goats and to a lesser degree, cattle, horses, pigs, and deer; however, little is 
known about the rate of chlamydial infections because of the lack of epidemiological evidence [8]. Diagnosis of chlamydial infections can be attempted by various detection methods, including culture, antigen detection, serology, and nucleic acid amplification. However, in spite of various available methods (e.g. staining and microscopic examination, isolation, molecular and serological diagnosis) the detection of Chlamydiae in clinical specimens remains a major challenge and need to high experiences [9]. This bacterium is a highly homogeneous species with low genetic heterogeneity. C. abortus as the recently emerged species, is closely related to more diverse $C$. psittaci with more diversity in genetics, host association and disease pathology. Also, gene-flow could be occurred between C. psittaci and C. abortus during host cell coinfection with these two species $[10,11]$. Gene exchanging by bacteriophage is probable since some bacteriophages have been identified for C. abortus and C. psittaci [12]. Gene diversity within the genus is much lower in $C$. abortus compared to other species; moreover, strong geographical signatures within phylogeny were reported [13]. By sequencing of C. abortus core genome, several major regions with high variability observed which encode highly variable proteins such as TMH (transmembrane head protein) and Pmp (polymorphic membrane protein) families. These variable loci are source of diversity in disease causation and host tropism in these bacteria $[14,15]$.

Multiple loci variable number of tandem repeats analysis (MLVA) is a method which utilizes the naturally occurring variation in the number of tandems repeated in a set of variable number of tandem repeats (VNTR) loci found in the genome of most bacterial species [16]. The genomic study of bacteria is an applicable approach not only to detection of infection sources and resistance to antibiotics, but also to studying the relationship of genomic profile with the intensity and type of clinical signs and host tropism [17-19]. This method has been used successfully for C. abortus and $C$. psittaci typing, the causative agents of ovine and avian chlamydiosis, respectively. The recently developed MLVA system is capable of classifying a panel of 111 C. abortus isolates into 6 genotypes based on five VNTR loci and their respective PCR fragments [6]. Also, 38 reference strains of $C$. psittaci with 5 selected VNTR primers as well as 6 C. abortus prototype strains with the 8 VNTR primers were established for type C. psittaci [20]. The isolation of each pathogen could be useful in experimental studies for the identification of pathogenesis or production of vaccines. Until now, many serological and molecular studies have been conducted on $C$. abortus infections; despite this, they have been unsuccessful in isolating it. Also, no study has reported the genetic heterogeneity in C. abortus isolates in Iran. Therefore, the present study aimed at the isolation and identification of genetic heterogeneity among $C$. abortus strains in the ruminants of Iran. Results of this research could act as a basis for epidemiological and control programs in Iran.

\section{Methods}

A schematic of the protocol we developed to study of C. abortus MLVA typing in aborted fetus is shown in below.

liver, spleen, and abomasum of aborted fetus in SPG transport medium.

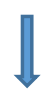

DNA extraction and C.abortus infection detection by real time PCR and conventional PCR.

$$
\downarrow
$$

MLVA typing of all positive samples / Isolation by Yolk sac inoculation of some of positive samples.

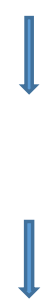

Confirmation of C.abortus infection in chicken emberyo by conventional PCR and staining.

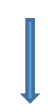

Inoculation of infected yolk sac to L929 cell line.

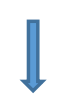

Confirmation of C.abortus infection in cell line by staining, conventional PCR, fluorescent Ab, immunodot.

\section{Sample collection}

A total of 117 aborted fetuses (9 cattle and 108 sheep from Khuzestan and Chaharmahal/ Bakhtiari provinces) were collected from different herds located in the south-west of Iran (from 2014 to 2016). Samples (liver, spleen, and abomasum) were collected from the 
aborted fetuses and kept in Sucrose Phosphate Glutamate (SPG) transport medium and settled at $-70^{\circ} \mathrm{C}$. Strict aseptic protocols were used for each sample to avoid cross-contamination. Two sampling provinces are demonstrated in Fig. 1.

\section{Detection of C. abortus infected samples}

Chlamydial infection of all studied samples was evaluated by Chlamydiales-specific PCR [21]. Genomic DNA was extracted from each sample using commercial DNA extraction Kit (CinaGen, Iran) in accordance to the manufacturer's instructions.

The PCR assay was performed in a total volume of $25 \mu \mathrm{L}$, includ ing bacterial DNA $(5 \mu \mathrm{L})$, forward and reverse primers $(1 \mu \mathrm{L} ; 0.1 \mu \mathrm{M}), 2 \mathrm{X}$ PCR Master Mix $(12.5 \mu \mathrm{L}$; Ampliqon), and nuclease-free water $(5.5 \mu \mathrm{L})$. The temperature of the protocol was $94^{\circ} \mathrm{C}$ for $10 \mathrm{~min}$ (primary denaturation), 35 cycles of $94^{\circ} \mathrm{C}$ for $30 \mathrm{~s}$ and $48^{\circ} \mathrm{C}$ for $30 \mathrm{~s}$. Nuclease-free water as negative control and C. abortus s26/3 as positive control. Primers sequence and aim gene (16s-23s spacer region) were shown in Table 1.

C. abortus infection in the positive samples from the primary stage was detected by real-time PCR designed by Panchev et al. (2009) based on the presence of ompA gene. The C. abortus s26/3 and C. psittaci $6 \mathrm{BC}$ used as the positive controls, with nuclease free water serving as the negative control.

The Real-time PCR reaction was carried out in final volume of $25 \mu \mathrm{L}$ by the Biosystem step one (ABI) device. Each reaction was duplex and consist of $3 \mu \mathrm{L}$ of extracted DNA, $1 \mu \mathrm{L}$ of each primer (final concentration of $0.6 \mu \mathrm{M}), 2 \mu \mathrm{L}$ of TaqMan probe $(0.3 \mu \mathrm{M}$ concentration). The temperature of the protocol was $95^{\circ} \mathrm{C}$ for $10 \mathrm{~min}$ (primary denaturation), 45 cycles of $95^{\circ} \mathrm{C}$ for $15 \mathrm{~s}$ and $60^{\circ} \mathrm{C}$ for $45 \mathrm{~s}$ [23]. Primers sequence and probs were shown in Table 2.

\section{Multi-locus VNTR analysis (MLVA)}

MLVA genotyping was carried out by targeting five tandem repeat loci (ChlaAb_457, ChlaAb_581, ChlaAb_620, Chla Ab_914 and ChlaAb_300) as described previously [6]. Initially, PCR was performed on the C. abortus S26/3 strain as the control.

For the VNTR amplifications, PCR was performed in a total volume of $25 \mathrm{~mL}$ with $1 \mathrm{U}$ of Hot Start Taq DNA polymerase (CinnaGen, Iran). The sequence of the designed VNTR primers based on the whole genomic sequence of $C$. abortus $S 26 / 3$ is shown in Table 3. Five microliters of the amplification product were loaded in

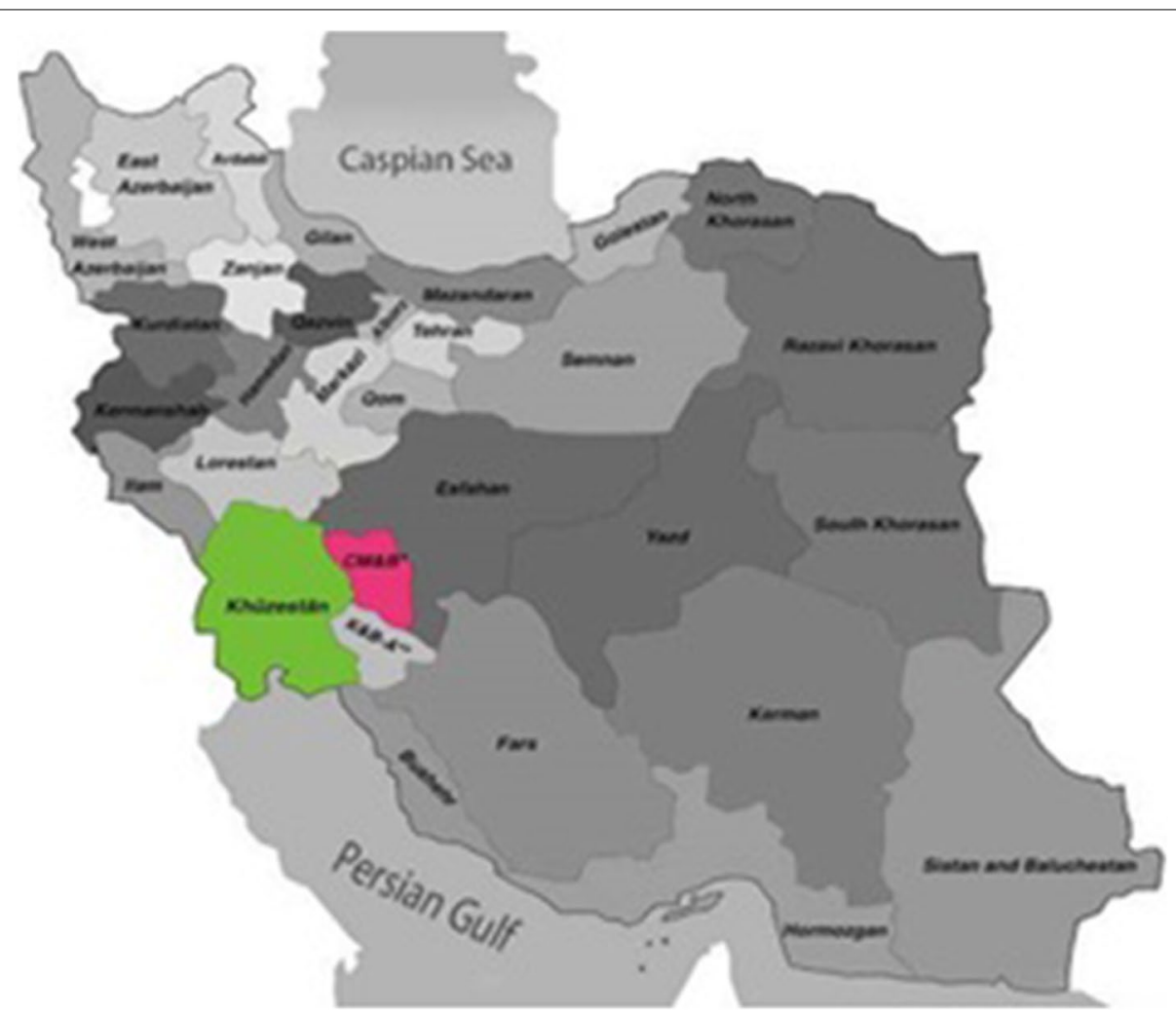

Fig. 1 Demonstration of geographical situation of two studied provinces 
Table 1 The sequence of primers of Chlamydiales and C. abortus used in the PCR assay

\begin{tabular}{|c|c|c|c|}
\hline References & Length (bp) & Sequence $\left(5^{\prime}-3^{\prime}\right)$ & Genes \\
\hline Borel et al, 2006 [21] & $352 b p$ & $\begin{array}{l}\text { Forward 5'-CAA GGT GAG GCT GAT } \\
\text { GAC-3' } \\
\text { Reverse 5'-TCG CCT KTC AAT GCC } \\
\text { AAG-3' }\end{array}$ & $\begin{array}{l}\text { Chlamydiales } \\
16 \mathrm{~s}-23 \mathrm{~s} \text { spacer region } \\
\text { (100pmoles/ ul) }\end{array}$ \\
\hline Longbottom et al 2002 [22] & $222 b p$ & $\begin{array}{l}\text { Forward 5'- TTTTCAGGATCCTATTGTCCT } \\
\text { CCAGGCA - } 3^{\prime} \\
\text { Reverse 5'- GTGTCGACATCAGCATAA } \\
\text { ATAGCCCCG }-3^{\prime}\end{array}$ & $\begin{array}{l}\text { Chlamydia. abortus } \\
\text { pmpl gene } \\
\text { (100 pmoles/ ul) }\end{array}$ \\
\hline
\end{tabular}

Table 2 Primers and TaqMan probes used for detection of C. abortus and internal amplification control by real-time PCR

\begin{tabular}{lll}
\hline Name & Sequence & $\begin{array}{l}\text { Amplicon } \\
\text { size } \mathbf{( b p )}\end{array}$ \\
\hline CpaOMP1-F & 5-GCAACTGACACTAAGTCG & 82 \\
CpaOMP1-R & GCTACA-3 & \\
CpaOMP1-Sa & 5-ACAAGCATGTTCAATCGA & \\
& TAAGAGA-3 & \\
& FAMb-TAAATACCACGAATG \\
& GCAAGT & \\
EGFP-1-F & TGGTTAGCG-TAMRAC & \\
EGFP-10-R & 5-GACCACTACCAGCAGAAC 177 \\
EGFP-HEXd & AC-3 & \\
& 5-CTTGTACAGCTCGTCCAT & \\
& GC-3 & \\
& HEXd- & \\
& AGCACCCAGTCCGCCCTG & \\
& AGCABHQ1 & \\
& e &
\end{tabular}

a Conventional TaqMan probe

b FAM 6-carboxy-fluorescein

c TAMRA 6-carboxy-tetramethylrhodamin

d HEX hexachlorofluorescein

e Black hole quencher

$4 \%$ agarose gel. The agarose gel was colored with safestain $(3-5 \mu \mathrm{L} / 100 \mathrm{cc})$ (CinnaGen, Iran) and was then visualized under UV light and photographed.

\section{Isolation and identification}

A number of positive samples (5 samples of 5 aborted fetus) from the previous stage were selected for inoculation in chicken embryos (eggs were incubated at $37.8^{\circ} \mathrm{C}$ and $5 \% \mathrm{CO}_{2}$ with a relative humidity of $65 \%$ for 7 days). Before yolk sac inoculation, samples (liver, spleen, and abomasum secretion) were homogenized (1\% in sterile PBS) and treated with different antibiotics, such as vancomycin $(1 \mathrm{mg} / \mathrm{mL})$, gentamycin $(200 \mu \mathrm{g} / \mathrm{mL})$, and amphotericin $\mathrm{B}(50 \mu \mathrm{g} / \mathrm{mL})$ and incubated at $4{ }^{\circ} \mathrm{C}$ for $24 \mathrm{~h}$ [24]. After inoculating $0.2 \mathrm{~mL}$ of the treated sample, the eggs were incubated in the conditions mentioned above for a 12-day post-infection (12 dpi). Eggs with embryonic mortality after 4 days of inoculation were evaluated to detect chlamydial inclusion bodies in the yolk sac cells by different staining methods such as Giemsa and Ziehl Neelsen and PCR assay [22, 25]. The confirmed positive samples by two staining methods and C. abortus specific PCR, were cultured in an L929 cell line (Pasteur Institute-Iran). For the development of a monolayer cell with the proper density $\left(1 \times 10^{5} \mathrm{cell} / \mathrm{mL}\right)$, the RPMI 1640 medium (Bioidea- Iran) supplemented with $10 \%$ fetal bovine serum (Bioidea, Iran), vancomycin $(100 \mathrm{mg} / \mathrm{mL})$, gentamycin $(50 \mu \mathrm{g} / \mathrm{mL})$ and amphotericin B $(50 \mu \mathrm{g} / \mathrm{mL})$ (Sigma, USA) was utilized. The cell line was inoculated with $500 \mu \mathrm{L}$ of the yolk sac specimen from the primary stage and incubated for 3 days at $37.8^{\circ} \mathrm{C}$ and $5 \% \mathrm{CO}_{2}$ with a relative humidity of $65 \%$. A monolayer cell culture without inoculation was used as the negative control culture. After $48 \mathrm{~h}$ of inoculation, the monolayer was trypsinized and a smear was prepared from the collected cells and was then stained with Giemsa [25] and Modified Macchiavello [26] to reveal the inclusion bodies and be

Table 3 Primer sequences for detection of five tandem repeat loci for genotyping of C. abortus using MLVA method

\begin{tabular}{llllr}
\hline Name & Forward primer (5-30) & Reverse primer (50-30) & $\begin{array}{l}\text { Repeat unit } \\
\text { (bp) }\end{array}$ & $\begin{array}{l}\text { repetition } \\
\text { number }\end{array}$ \\
\hline ChlaAb_300 & AGACCTAAAGCGCCACCTTCA & ATGCGCCAATCTATACGCTGA & 9 & 3.0 \\
ChlaAb_457 & GTACAAAAAAAACGTAGCAGCAAGAA & CACGTTGGCAAGAAGCTGTGT & 28 & 2.8 \\
ChlaAb_581 & ACAGCACCAGCATTAGCCG & TGGATAGTTGTCGCTGGTGG & 15 & 2.1 \\
ChlaAb_620 & ATGCTATAATTGCTTAGTTTTTTAACATTG & CACATGCCGCCCTGAAC & 11 & 3.6 \\
ChlaAb_914 & TTTAAAGTTTCCGTATCTTTGTAATCGAT & TTTTAGAATTCGCATCATTACCAGAA & 15 & 2.3 \\
\hline
\end{tabular}


confirmed by PCR assay [22]. Confirmation of Chlamydiae infection in chicken embryo and L929 cell line was conducted by PCR. Thereby, each reaction was carried out in a final volume of $25 \mu \mathrm{L}$ containing $1 \times$ PCR buffer, $0.5 \mu \mathrm{M}$ of each primer set, $200 \mu \mathrm{M}$ of the four deoxynucleoside triphosphates (dNTPs), $2 \mathrm{mM} \mathrm{MgCl}_{2}$, and $0.5 \mathrm{U}$ of Taq polymerase (SinaGen, Iran). The primers used for the detection of Chlamydiales and C. abortus are shown in Table 1. By means of these primers, $16 \mathrm{~s}-23 \mathrm{~s}$ spacer regions in chlamydia spp. and pomp $90-3$ gene in C. abortus could be detected. PCR reactions were performed in an Eppendorf thermo-cycler (Eppendorf, Germany) under the following conditions: initial denaturation for $10 \mathrm{~min}$ at $94^{\circ} \mathrm{C}$; 35 cycles of $30 \mathrm{~s}$ at $94^{\circ} \mathrm{C}$, annealing for $30 \mathrm{~s}$ at $48^{\circ} \mathrm{C}$ (for $16 \mathrm{~s}-23 \mathrm{~s}$ spacer region and pomp $90-3$ genes), extension for $45 \mathrm{~s}$ at $72{ }^{\circ} \mathrm{C}$ and final extension step at $72^{\circ} \mathrm{C}$ for $10 \mathrm{~min}$. The PCR products were subjected to electrophoresis for $1 \mathrm{~h}$ at $70 \mathrm{~V}$ in $1.5 \%$ agarose gel with 3-5 $\mu \mathrm{L} / 100$ cc of safe-stain (CinnaGen, Iran). The results were visualized and photographed under ultraviolet illumination.

\section{Indirect fluorescent antibody test}

The C. abortus infection of cells was confirmed by the indirect fluorescent antibody assay. For the preparation of an in-house anti-chlamydial antibody, 2 healthy female Albino rabbits were purchased from the experimental animal house of the related university and infected several times with the supernatant of $C$. abortus cell culture. Rabbits were retained under standard laboratory conditions and had free access to food pellets (Pars Animal Feed Co, Tehran, Iran) and tap water. Experiments were conducted according to the guide for the care and use of laboratory animals by the National Academy of Sciences of shahid chamran university, license no: EE/1400.3.02.32646/scu.ac.ir.

The monolayers of L929 cells on coverslips were infected with $100 \mu \mathrm{L}$ of positive samples and incubated for $48 \mathrm{~h}$ at $38^{\circ} \mathrm{C}$ with $5 \% \mathrm{CO} 2$. Subsequently, fixation was carried out by cold methanol for $20 \mathrm{~min}$ at room temperature and coverslips were dried and blocked with $1 \%$ BSA (Bovine serum albumin) diluted in PBS. After $1 \mathrm{~h}$ of incubation at $37^{\circ} \mathrm{C}$ in a humid chamber, coverslips were washed with PBST. Prior to being subjected to polyclonal rabbit anti-chlamydia-specific serum, coverslips were incubated with $0.1 \%$ Triton- 100 for $20 \mathrm{~min}$ at room temperature. Anti-chlamydia serum was diluted 1/100 in $\mathrm{PBS}+1 \% \mathrm{BSA}$ and incubated together with the infected cells on the coverslips for $1 \mathrm{~h}$ at $37^{\circ} \mathrm{C}$. Then, they were washed with PBST 4 times. Fluorescein isothiocyanatelabeled anti-rabbit antibody (Sigma-Aldrich, F9887) was diluted $1 / 200$ in PBST (PBS + 0.2\% Tween20) plus $1 \%$ BSA and incubated together with coverslips for $1 \mathrm{~h}$ at $37^{\circ} \mathrm{C}$. After 3 times of washing, the inclusion of the infected cells was observed using an IX-71 M fluorescence microscope (Olympus, Japan) at 4 and $40 \times 0.3$-fold magnification. Uninfected cells were used as the negative control in this method.

\section{Immunodotting assay}

In the current experiment, $0.1 \mu \mathrm{L}$ of different samples $(\mathrm{V}$; C. felis vaccine, $\mathrm{S}$; immune rabbit serum as positive control, A1 and A2; supernatant concentration of infected cell culture with $C$. abortus after 48 and $72 \mathrm{~h}$, respectively, F; supernatant concentration of infected cell culture with C. felis, $\mathrm{N}$; supernatant concentration of uninfected cell culture as negative control) were placed on nitrocellulose membrane. After drying at room temperature, the membrane was blocked with PBS $+0.2 \%$ Tween 20 for $2 \mathrm{~h}$. Polyclonal rabbit anti-chlamydia-specific serum was diluted $(1 / 200)$ in PBST (PBS+ $0.05 \%$ Tween 20$)$ and incubated for $1 \mathrm{~h}$. After washing 3 times with PBST, the mixture was adjusted with diluted $(1 / 1000)$ horseradish peroxidase anti-rabbit antibody (Sigma-Aldrich, A0545) in PBST for $1 \mathrm{~h}$. It was then washed with PBST 3 times and placed in chromogen substrate $\left(\mathrm{H}_{2} \mathrm{O}_{2}\right.$ and 4-Chloro-1- Naphthol) for $15 \mathrm{~min}$ at room temperature. Room temperature and shaking were used in all stages.

\section{Data analysis}

Data analysis was performed after carrying out the PCR of the VNTR loci and subsequent to determining the size of the PCR products on agarose gel via either capillary systems or an automated DNA sequence. The assessed PCR product size was used to calculate the number of repeated units in each locus. The flanking regions with known sizes were subtracted from the PCR product size which resulted in the net size of the repeat region. This size was divided by the repeated unit size which eventually revealed the number of repeats. There was a negligible inaccuracy in sizing, but for most of the parts, it did not prevent the assessment of the number of repeats [27]. Amplicons size was determined manually using a $100 \mathrm{bp}$ ladder (CinnaGen, Iran). Based on the differences in the number and weight of the fragments, genotypes were assigned following MLVA fingerprint analysis. The bands or fragments were compared using the Dice method and clustered by the Unweighted Pair-Group Method with Arithmetic Mean (UPGMA) by referring to insilico.ehu. es online data analysis service.

\section{Results}

Generally, Chlamydial infection was detected in 40 samples $(34.1 \%)$ by order-specific conventional PCR. The infected samples in the 2 studied provinces consisted of 
37 sheep and 3 cows. The number of positive samples in Charmahal/Bakhtiari (38/61) was more than that in Khuzestan (2/56) province. By species- specific real-time PCR, C. abortus infection was confirmed in all of them and coinfection was reported in any of the 40 studied samples. Results of primary selection of infected samples by Chlamydiales-specific PCR are shown in Table 4.

For isolation, after 1 passage of each positive sample in the chicken embryo, we demonstrated cytoplasmic inclusions in the yolk sac membrane of dead fetus (Fig. 2). By culturing the primary infected yolk sac in an L929 cell line, various sizes of dense cytoplasmic inclusions were detected in trypsinized and non trypsinized infected cell stained smears (Fig. 3). Also, C. abortus infection in the cell line was confirmed by producing $222 \mathrm{bp}$ fragments by species-specific conventional PCR (Fig. 4).

Cell infection was confirmed by indirect fluorescent antibody test and immunodotting assay. The manifestation of different sizes and densities of fluorescent cytoplasmic inclusions was a sign of cell infection as shown in Fig. 5. As regards the immunodotting assay, a strong reaction of $\mathrm{V}$ (C. felis vaccine), $\mathrm{S}$ (immune rabbit serum as positive control), A1(supernatant concentration of infected cell culture with C. abortus after $48 \mathrm{~h}$ ), A2 (supernatant concentration of infected cell culture with C. abortus after $72 \mathrm{~h}$ ) and $\mathrm{F}$ (supernatant concentration of infected cell culture with $C$. felis) samples with polyclonal rabbit anti-chlamydia-specific serum was observed although no reaction with the $\mathrm{N}$ (supernatant concentration of uninfected cell culture as negative control) sample was detected.

The results of MLVA analysis in 40 strains (one strain from each aborted fetus) are shown in Figs. 6 and 7. Generally, $32 \%$ of C. abortus strains (13/40) were grouped in MT1 as the main MT type. Three bovine strains from Charmahal/Bakhtiari were grouped in MT1(one strain) and MT6 (two strains). The bovine strains were similar to the clusters from sheep in terms of size (base pair). Following MT1 as the main type, MT6 type with 8 strains and MT2 and MT3 types with 6 strains were in the second and third places, respectively. The minimum number of strains was in MT4 and MT5 groups with merely 2 and 1, respectively (Table 5). All MLVA types were detected

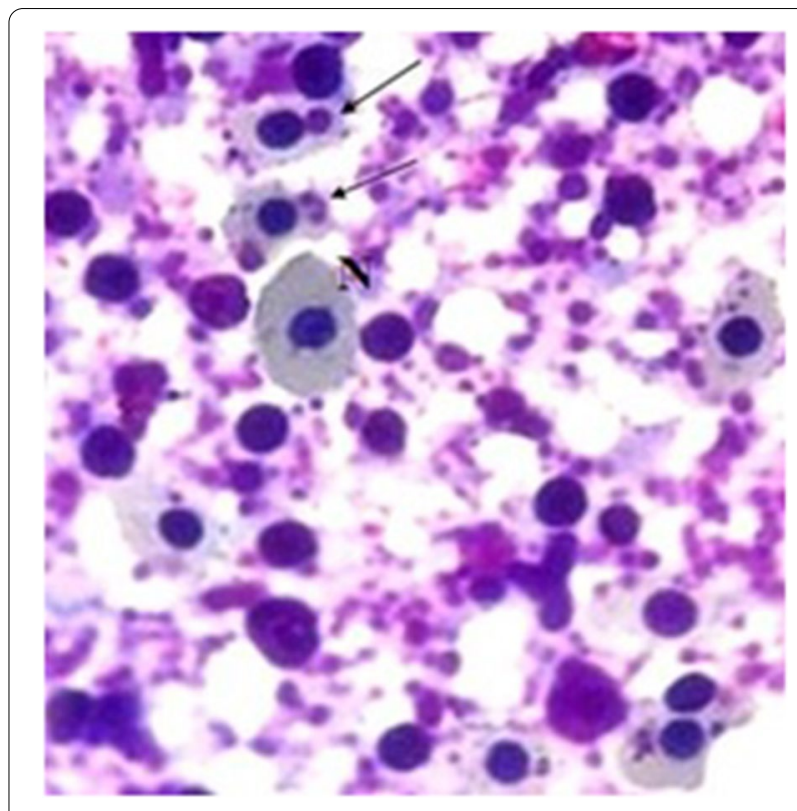

Fig. 2 Giemsa staining of inoculated egg yolk sac with positive sample after $72 \mathrm{~h}$ (ED11). $\mathrm{N}$ and arrows demonstrate normal cells and inclusion in the infected cells, respectively

in the collected strains from Charmahal/Bakhtiari but only 2 types (MT1 and MT3) were reported in those from Khuzestan. The ChlaAb_457 genome (CAB398 coding for a histone-like protein) with $385 \mathrm{bp}$ fragment size was detected in $39(97.5 \%)$ of the C. abortus strains while the ChlaAb_620 genome (CAB541 coding for a conserved membrane protein) with $163 \mathrm{bp}$ fragment size was not detected in any of the strains. According to the attained results, the most and the least variations were detected in MT7 strains and MT3 strains, respectively. In the present study, the basis of the classification of the strains in different clusters was genetic similarity, accounting for more than $95 \%$. The genetic affinity observed among the strains in cluster 1 was reported to be higher than those in other clusters despite the differences in sampling time and geographical areas. Three bovine strains were settled in 2 different clusters. Also, 2 sheep strains in Charmahal/ Bakhtiari were detected as singleton with different patterns of VNTRs and sampling time. Significantly,

Table 4 Results of primary selection of infected samples by Chlamydiales-specific PCR

\begin{tabular}{|c|c|c|c|c|c|}
\hline \multirow[t]{2}{*}{ Host type } & \multicolumn{2}{|l|}{ Positive } & \multicolumn{2}{|l|}{ Negative } & \multirow[t]{2}{*}{ Prevalence $\mathrm{Cl}$ 95\% } \\
\hline & sheep & cow & sheep & cow & \\
\hline Khuzestan & $2(3.7 \%)$ & $0(0 \%)$ & $54(96.42 \%)$ & $0(0 \%)$ & $3.57 \%(0.048-0.013)$ \\
\hline Charmahal/bakhtiari & $35(67.3 \%)$ & $3(33.33 \%)$ & $17(32.69)$ & $6(66.66 \%)$ & $62.29 \%(0.742-0.498)$ \\
\hline total & 37 & 3 & 71 & 6 & $34 \%(0.426-0.254)$ \\
\hline
\end{tabular}



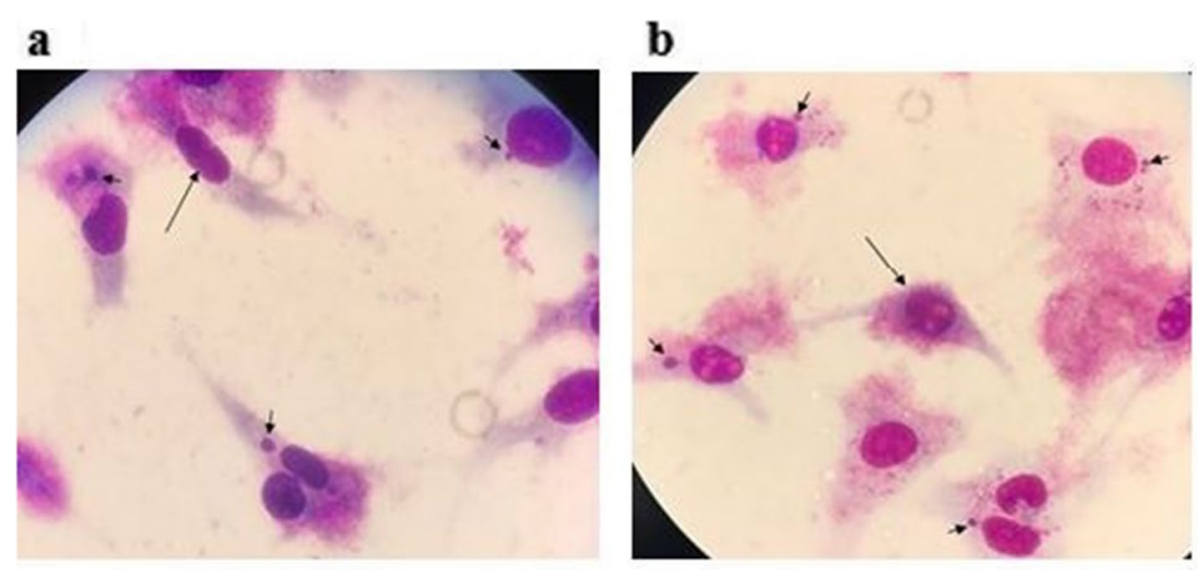

C

\section{d}
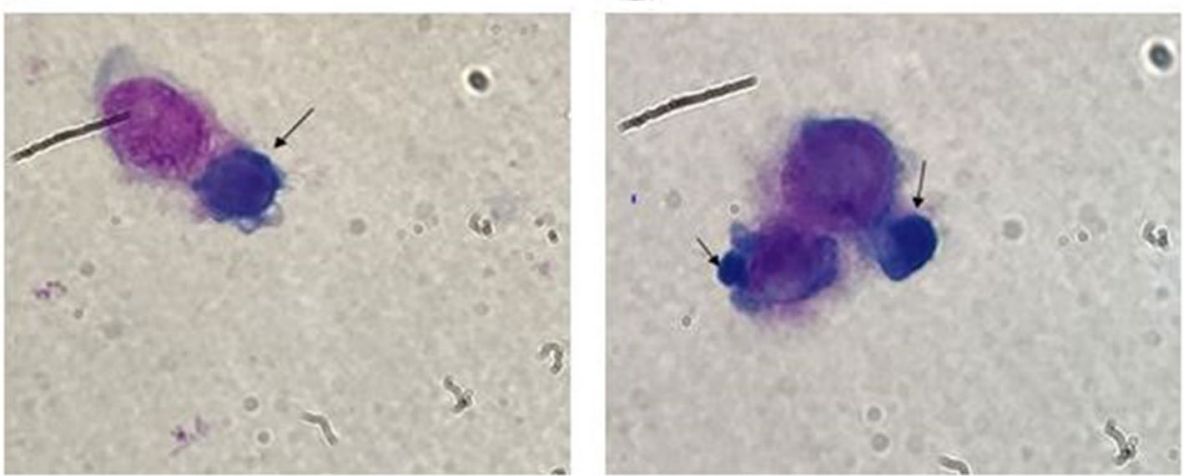

Fig. 3 Morphology of C. abortus inclusion bodies (arrows) in L929 cells $\times 100$. a \& b; Giemsa staining of non- trypsinated infected cells; the long and short arrows show the normal and infected cells with inclusion, respectively. C \& d; Giemsa staining of inclusion bodies (arrows) in trypsinated C. abortus infected cells

strains 21 and 31 with different sampling time and geographical area were grouped in MT1. In Fig. 6, additional data about variations in the loci subjected to MLVA in the studied strains are demonstrated.

\section{Discussion}

Abortion is economically important in many types of ruminants in Europe, North America, Africa, and Asia. C. abortus gives rise to reproductive disorders, inflammation of the epididymis, pneumonia, arthritis and conjunctivitis. It is even found in the feces of healthy sheep and goats and could also be a zoonotic risk for pregnant women $[21,22,28]$.

In several studies, molecular techniques, such as various PCR assays and real-time PCR based on different goal genes (ompA, IGS-SrRNA, 16SrRNA, pomp90-3, pomp $90-4$, and $16 \mathrm{~s}-23 \mathrm{~s}$ spacer region) have been used for the detection or phylogenic analysis of C. abortus strains in the aborted fetuses of ewes [23, 29-31].
Certainly, these methods have different sensitivity and specificity.

The role of Chlamydiosis in different types of animals in Iran, particularly in the 2 studied provinces, has been investigated by serologic and molecular tests; however, due to the complications of the culture method and common clinical signs, isolation has never been the focal point of research. Undoubtedly, isolation and genotyping of $C$. abortus were conducted by the present research, is the first attempt to carry out in-depth studies in this context in Iran.

In the present study, for the primary detection of $C$. abortus in the infected samples, real-time PCR was used. By this method, the probability of an error in the differentiation of C. psittaci and C. abortus or missing the coinfection with 2 species is the least. Based on the results, the Chlamydial infection of ruminants in the present research was $34.1 \%$ whereas the $C$. abortus infection revealed to be $100 \%$, which are considerably 

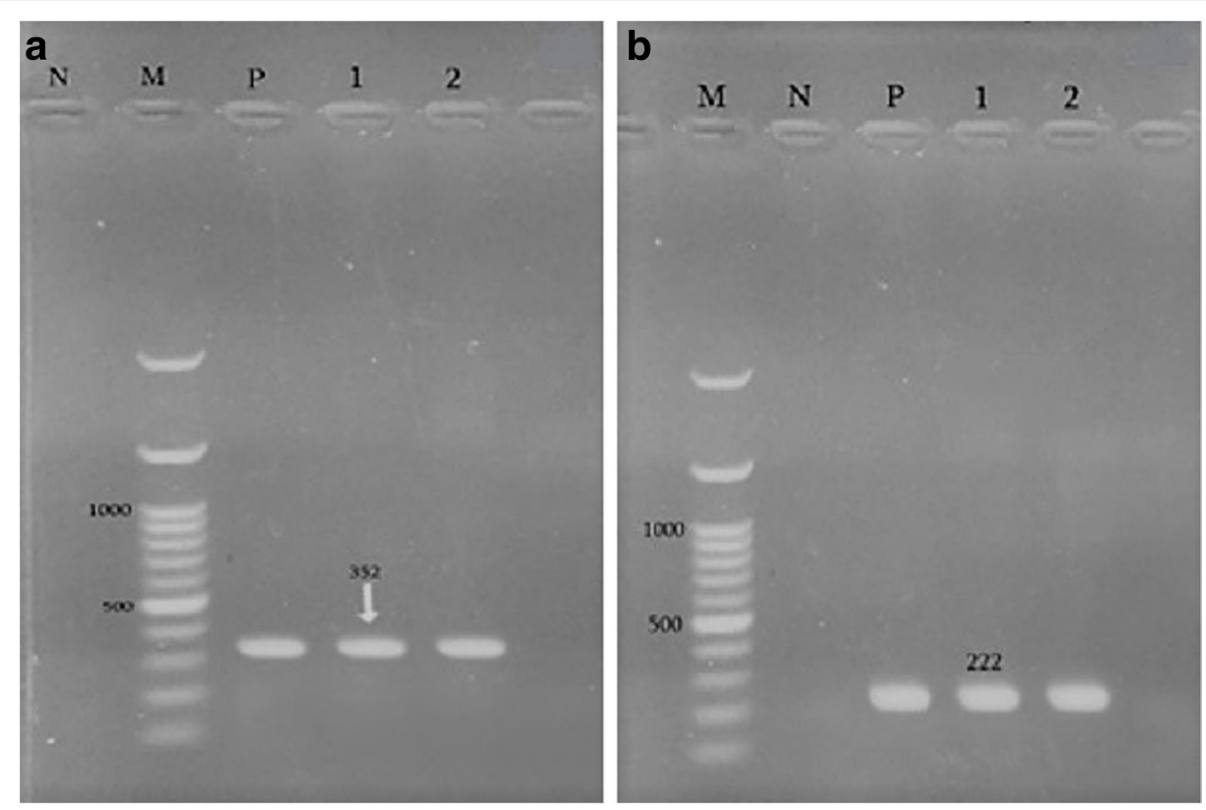

Fig. 4 (A) PCR results with Chlamydiales specific primers CIGS-1f/ cIGS-1r in agarose gel N- negative control; $\mathrm{M}$ - molecular mass standard 100 bp ladder; P- positive control (352 bp); lines 1 and 2- tested samples. (B) PCR results with C. abortus pomp90-3 specific primers. N- negative control; Ppositive control (222 bp); Lines 1-3 tested samples; M - molecular mass standard 100 bp ladder.

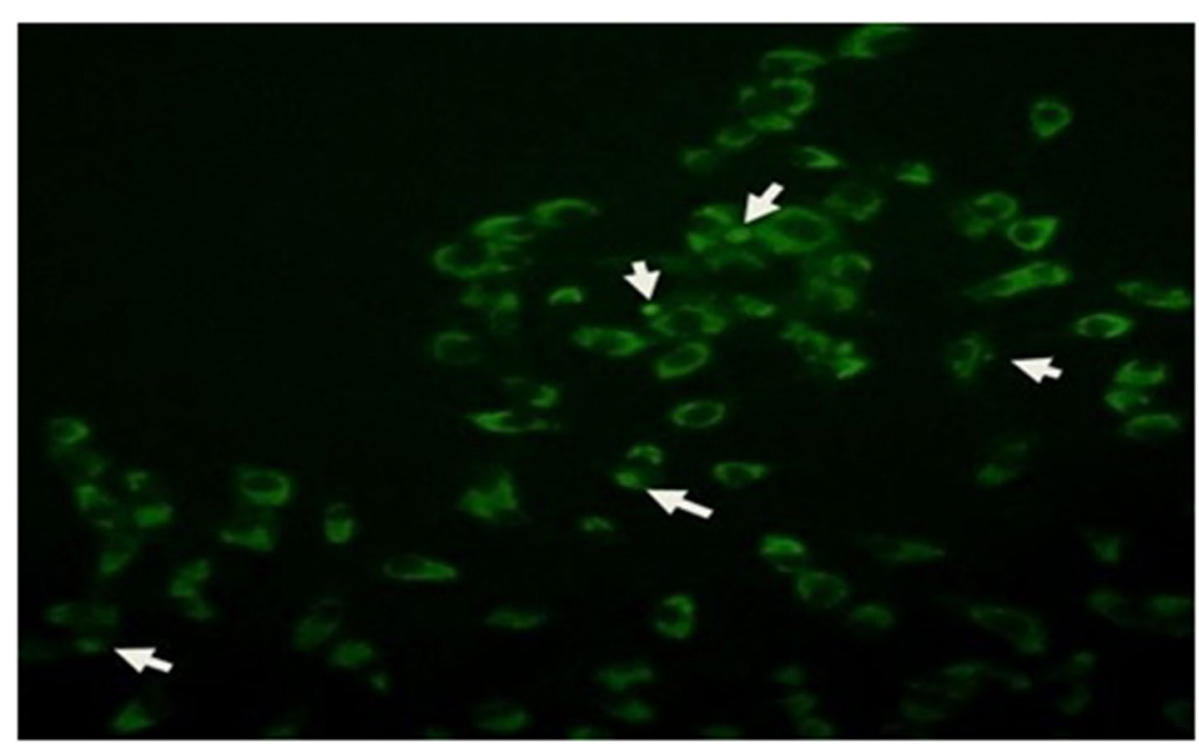

Fig. 5 Indirect fluorescent antibody staining of non trypsinated C. abortus infected cells; Inclusion and infected cells are demonstrated with arrow

high percentages. It is worth noting that in spite of the equal number of collected samples in 2 studied provinces, the detected positive samples in Charmahal/ Bakhtiari outnumbered those in Khuzestan. This could be related to more traditional training of ruminants in Charmahal/Bakhtiari compared to Khuzestan.
It is necessary to show the relationship between pathogenic and non-pathogenic strains as well as the distribution patterns of the pathogenic strains in the region due to being regarded as determining factors to control pathogenic strains. Pathogenic typing can assist us in understanding the pathogenic relationship between the 


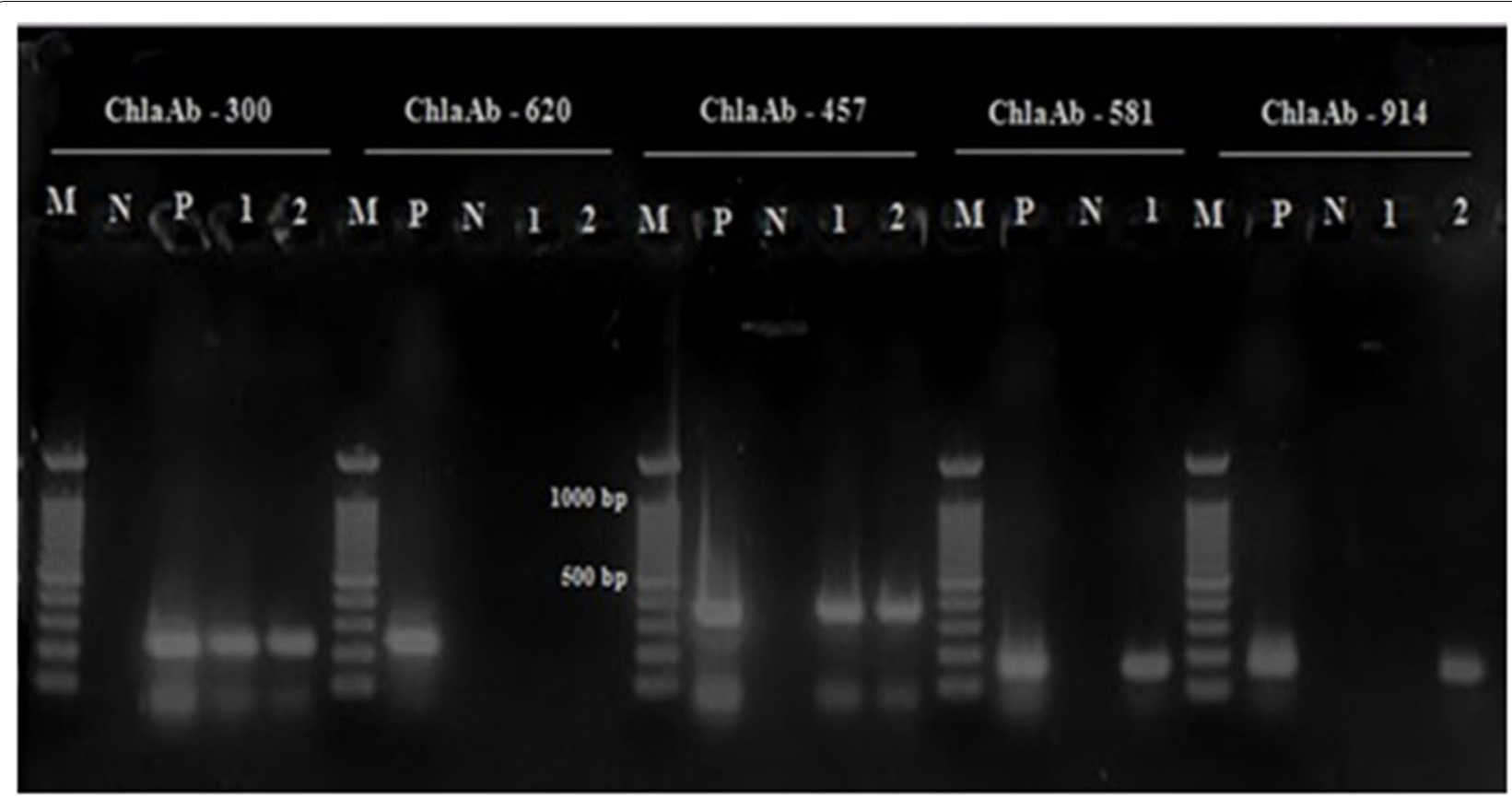

Fig. 6 MLVA profile of C. abortus in 2 studied samples. M - Molecular mass standard 100 bp ladder; N-negative control; P- C. abortus S26/3 as positive control; lines 1 and 2- tested samples

prevalent types and their sources (human or animal) and the differentiation of current and new infections [32].

The efficacy of the MLVA method has been confirmed by several researchers for the purpose of typing different microorganisms. Laroucau et al. (2009) used 8 selected loci in 9 standard strains of $C$. psittaci in birds for typing 150 clinical C. psittaci isolates with different hosts in various areas. They stated that this method has a higher diagnostic value and more sensitivity compared with serotyping by ompA gene sequencing. Genotyping of $C$. abortus strains based on five selected loci (ChlaAb_457, ChlaAb_581, ChlaAb_620, ChlaAb_914, and ChlaAb_300) has been shown to be appropriate for clinical samples [6].

Li et al. (2015), studied 135 samples (9 aborted fetuses, 126 vaginal swabs) of yak papulation in China. C. abortus infection was reported in 9 aborted fetuses $(100 \%)$ and 30 vaginal swabs (23.81\%). MLVA typing of 4 isolated strains in this study was grouped in MT2 [33].

Also, Malal and Turkyilmas in Turkey studied the material samples of abortion in 267 cattle, 380 sheep, 70 goats and 13 water buffaloes. C. abortus infection was reported in $11.9 \%$ of the studied samples and as a result of MLVA typing, MT2 was found as the dominant genotype (93.1\%). Certainly, genotype 3,4 and 5 were involved in the infections [34].
In the present research, a study on genetic linkage among C. abortus strains in 2 provinces of Iran was carried out for the first time, using MLVA. According to our findings, there was roughly 80 to $100 \%$ similarity between sheep and bovine $C$. abortus strains in the 2 studied regions, respectively. The MLVA typing method, based on the analysis of 5 VNTR loci, enabled the clustering of $40 \mathrm{C}$. abortus strains into 8 genotypes; this showed genotyping diversity among $C$. abortus strains which included 8 different MLVA types (MT1-8). Variation of MTs in Charmahal/Bakhtiari (MT1- MT8) was more than that of Khuzestan (MT1, MT3) province, with due attention to study of different number of positive samples in two areas. There was a close genetic linkage among the strains from Khuzestan. Furthermore, the occurrence of common clones from Khuzestan and Chaharmahal/ Bakhtiari indicated a genetic similarity in C. abortus strains from these regions and between the sheep and cattle strains. This provides evidence for the transmission risk of $C$. abortus ruminant infection from these areas. In the same vein, Seth-Smith et al. (2017) reported that the diversity within C. abortus as compared to other species is much lower; moreover, the genome of $C$. abortus is highly stable [13]. Therefore, suitable strategies should be employed to curb the possible spread of infection due to C. abortus in sheep and cattle in the studied regions. Due to the proximity of these 2 provinces and the migration 


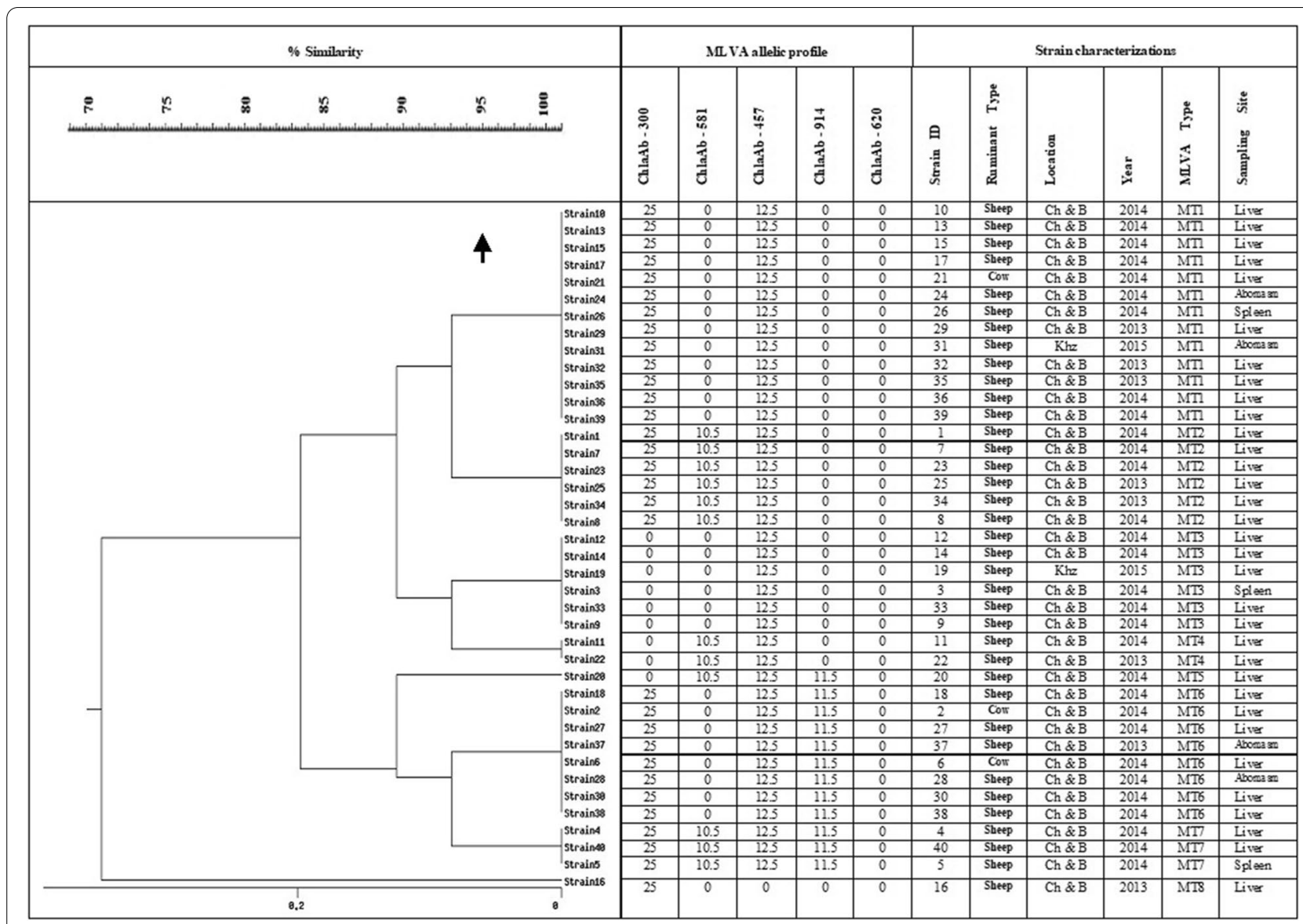

Fig. 7 Dendrogram of C. abortus based on MLVA analysis. Results are compared

using the Dice method and clustered by UPGMA.

Table 5 Genotypic classification according to animal species

\begin{tabular}{|c|c|c|c|c|c|c|c|c|}
\hline Animal species & MT1 & MT2 & MT3 & MT4 & MT5 & MT6 & MT7 & MT8 \\
\hline Sheep & $12(92.3 \%)$ & $6(100 \%)$ & $6(100 \%)$ & $2(100 \%)$ & $1(100 \%)$ & $6(75 \%)$ & $3(100 \%)$ & $1(100 \%)$ \\
\hline Cow & $1(7.69 \%)$ & - & - & - & - & $2(25 \%)$ & - & - \\
\hline total & $13(32.5 \%)$ & $6(15 \%)$ & $6(15 \%)$ & $2(5 \%)$ & $1(2.5 \%)$ & $8(20 \%)$ & $3(7.5 \%)$ & $1(2.5 \%)$ \\
\hline
\end{tabular}

of animals between them, these findings were expected relatively.

In the current research, MT1 was reported as the dominant type but in another research regarding $C$. abortus in Asia (Turkey and China), MT2 turned out to be dominant. Considering the common border between Iran and Turkey and also the probability of animal interchange, augmented similarity in MLVA type is expectable. Any investigation regarding C. abortus genotyping in areas where Turkey shares border with West Azarbayejan province can shed light on such variations.
The exact reason behind different predominant $C$. abortus MLVA type in areas with no common borderline such as China or any European country could be due to various management and hygienic factors.

Siarkou et al. (2015) reported 7 types in the MLVA genotyping of 94 ruminant $C$. abortus isolates, with the highest repetition variation occurring in MT2 [35]. The correlation between repetitive locus number and the virulence of strains was mentioned in the Laouracu et al. (2008) study [20]. In the present research, 3 strains were demonstrated with 4 repetitions of 5 loci 
which are more acute compared with other strains. A survey of the repetitive profile (5 studied loci) in 40 isolates showed that the ChlaAb_457 and ChlaAb_620 loci appeared in 97.5 and $0 \%$ of the isolates, respectively.

The collection of samples was carried out over a period of 3 years (2014-2016); therefore, the time difference can also be investigated in the present research. The highest and the lowest variations were observed in MT1 and MT7, respectively. The isolates in the other types (MT2, MT3, MT4, MT5, and MT6) were a combination across 3 years which could be indicative of the genetic relationship between these types.

\section{Conclusions}

For the first time, the prevalence of $C$. abortus in ruminants of Iran was detected by real- time PCR. Based on results, $C$. abortus could be reported as important agents responsible for ruminant abortion in Khuzestan and Charmahal/Bakhtiari provinces. In addition to, economic loos aspect of Chlamydial abortion, geographical situation of Khuzestan province and its important role in animal transport between internal provinces and neighbor countries such as Iraq, are strong reasons for special attention to review of prevention management in this area. Comparison with neighbor countries such as Turkey, $C$. abortus abortion percentage in small ruminants was 2-3 times more in Iran, which could be related to more restrict managements in this country. By genotyping of $C$. abortus in this research for the first time in Iran, high genotype diversity from MT1 to MT8 was detected. Although, diverse with another studies in different part of the world (e.g. Turkey, France, UK), MT1 was reported as dominant genotype in studied areas. In spite of, significant aspects of this research, necessity of study of $C$. abortus abortion rate in humans and typing of C. abortus in another areas of Iran is stable and recommendable.

\begin{abstract}
Abbreviations
BSA: Bovine serum albumin; C.abortus: Chlamydia abortus; C. psittaci: Chlamydia psittaci; dpi: day post-infection; MLVA: multiple loci variable number of tandem repeats analysis; MT: MLVA type; PBS,: Phosphate Buffer Saline; PBST: PBS + 0.2\% Tween20; Pmp: polymorphic membrane protein; RPMI 1640 medium: Roswell Park Memorial Institute Medium; SPG: Sucrose Phosphate Glutamate; TMH: transmembrane head protein; UPGMA: Unweighted PairGroup Method with Arithmetic; VNTR: variable number of tandem repeats.
\end{abstract}

\section{Acknowledgements}

Also, it is necessary to thank Professor Borel (Institute of Veterinary Pathology, University of Zurich, Switzerland) and Professor Sareyyupoglu (Ankara university) as provider of C. abortus $s 26 / 3$ and C. psittaci 6 BC positive controls, respectively. Also, Professor Laroucau (Unité Zoonoses Bactériennes, France) for their helpful guidance.

\section{Authors' contributions}

N.M.B and S.B.: wrote the main drafted of manuscript, S.B.: prepared Figs 1,2, 3, 4, 5 and 6, L.SH.: MLVA assay, M.G.: immunofluorescent assay, H.M.: sample collection. The authors read and approved the final manuscript.

\section{Funding}

This study was funded by Shahid Chamran University of Ahvaz.

\section{Availability of data and materials}

The datasets used and/or analyzed during the current study are available from the corresponding author on reasonable request.

\section{Declaration}

\section{Ethics approval and consent to participate}

The study weas conducted according to the National Academy of Sciences guide for the care and use of laboratory animals (EE/1400.3.02.32646/scu.ac.ir) and in compliance with best practice of veterinary care.

\section{Consent for publication}

Not applicable.

\section{Competing interests}

The authors declare that they have no competing interests.

\section{Author details}

${ }^{1}$ Post graduate of Veterinary Medicine school, Shahid Chamran University of Ahvaz, Ahvaz, Iran. ${ }^{2}$ Department of Pathobiology, Faculty of Veterinary Medicine, Shahid Chamran University of Ahvaz, Ahvaz, Iran. ${ }^{3}$ Department of Microbiology, Faculty of Medicine, Hamadan university of Medical Sciences, Hamadan, Iran. ${ }^{4}$ Department of Pathobiology, Faculty of Veterinary Medicine, Islamic Azad University of Shahrekord, Shahrekord, Iran.

Received: 21 September 2021 Accepted: 5 January 2022

Published online: 24 January 2022

\section{References}

1. Bommana S, Polkinghorne A. Mini review: antimicrobial control of chlamydial infections in animals: current practices and issues. Front Microbiol. 2019;10:113.

2. Laroucau K, Vorimore F, Aaziz R, Solmonson L, Hsia RC, Bavoil PM, et al. Chlamydia buteonis, a new Chlamydia species isolated from a red-shouldered hawk. Syst Appl Microbiol 2019; 42:125997.

3. Laroucau K, Ortega N, Vorimore F, Aaziz R, Mitura A, Szymanska-Czerwinska M, et al. Detection of a novel Chlamydia species in captive spurthighed tortoises (testudo graeca) in southeastern Spain and proposal of Candidatus Chlamydia testudinis. Syst Appl Microbiol. 2020;43:126071. https://doi.org/10.1016/j.syapm.2020.126071.

4. Rodolakis A. In vitro and in vivo properties of chemically induced temperature-sensitive mutants of Chlamydia psittaci var. ovis: screening in a murine model. Infect Immun. 1983:42:525-30 0019-9567/83/110525-06\$02.00/0.

5. Aitken ID, Longbottom D. Chlamydial abortion. Chlamydial infection. In: I.D. Aitken. Diseases of sheep, 4th Edition. Wiley Online library; 2007. p. 105-12.

6. Laroucau K, Vorimore F, Bertin C, Mohamad KY, Thierry S, Hermann W, et al. Genotyping of Chlamydophila abortus strains by multilocus VNTR analysis. Vet Microbiol. 2009;137:335-44. https://doi.org/10.1016/j.vetmic. 2009.01.029 Epub 2009 Jan 24.

7. Sait M, Clark EM, Wheelhouse N, Spalding L, Livingstone M, Sachse K, et al. Genetic variability of Chlamydophila abortus strains assessed by PCR-RFLP analysis of polymorphic membrane protein-encoding genes. Vet Microbiol. 2011;51:284-90. https://doi.org/10.1016/j. vetmic.2011.03.005.

8. Longbottom D, Coulter L. Animal chlamydiosis and zoonotic implications. J Comp Pathol. 2003;128:217-44. https://doi.org/10.1053/jcpa.2002. 0629. 
9. Poppert S, Essig A, Marre R, Wagner M, Horn M. Detection and differentiation of chlamydiae by fluorescence in situ hybridization. Appl Environ Microbiol. 2002;68:4081-9. https://doi.org/10.1128/aem.68.8.4081-4089. 2002.

10. Srinivasan T, Bruno WJ, Wan R, Yen A, Duong J, Dean D. In vitro recombinants of antibiotic-resistant Chlamydia trachomatis strains have statistically more breakpoints than clinical recombinants for the same sequenced loci and exhibit selection at unexpected loci. J Bacteriol. 2012;194:617-26. https://doi.org/10.1128/JB.06268-11 Epub 2011 Nov 28.

11. Joseph SJ, Marti H, Didelot X, Castillo-Ramirez S, Read TD, Dean D. Chlamydiaceae genomics reveals interspecies admixtureand the recent evolution of Chlamydia abortus infecting lower mammalian species and humans. Genome Biol Evol 2015 7: 3070-3084. doi:https://doi.org/10. 1093/gbe/evv201.

12. Pawlikowska-Warych M. S 'liwa-Dominiak J, Deptula W. chlamydial plasmids and bacteriophages. Acta. Biochim. Pol. 2015;62:1-6.

13. Seith-Smith HMB, Sánchez Busó L, Livingstone M, Sait M, Harris SR, Aitchison KD, et al. European Chlamydia abortus livestock isolate genomes reveal unusual stability and limited diversity, reflected in geographical signatures. BMC Genomics. 2017;18:344. https://doi.org/10.1186/ s12864-017-3657-y.

14. Thomson NR, Yeats C, Bell K, Holden MTG, Bentley SD, Livingstone D, et al. The Chlamydophila abortus genome sequence reveals an array of variable proteins that contribute to interspecies variation. Genome Res. 2005;15:629-40.

15. Low N, Broutet N, Adu-Sarkodie Y, Barton P, Hossain M, Hawkes S. Global control of sexually transmitted infections. Lancet. 2006;368:2001-16. https://doi.org/10.1016/S0140-6736(06)69482-8.

16. Vergnaud G, Pourcel C. Multiple locus VNTR (variable number of tandem repeat) analysis. In: In molecular identification, systematics, and population structure of prokaryotes. Berlin, Heidelberg: Springer; 2006. p. 83-104.

17. Van Belkum A, Scherer S, Van Alphen L, Verbrugh H. Short-sequence DNA repeats in prokaryotic genomes. Microbiol Mol Biol Rev. 1998;62:275-93 $1092-2172 / 98 / \$ 04.0010$

18. Jansen R, Embden JDV, Gaastra W, Schouls LM. Identification of genes that are associated with DNA repeats in prokaryotes. Mol Microbiol. 2002:43:1565-75. https://doi.org/10.1046/j.1365-2958.2002.02839.x.

19. Robbins A, Hanger J, Jelocnik M, Quigley BL, Timms P. Koala immunogenetics and chlamydial strain type are more directly involved in chlamydial disease progression in koalas from two south East Queensland koala populations than koala retrovirus subtypes. Nature. 2020;10:15013. https://doi.org/10.1038/s41598-020-72050-2.

20. Laroucau K, Thierry S, Vorimore F, Blanco K, Kaleta E, Hoop R, et al. High resolution typing of Chlamydophila psittaci by multilocus VNTR analysis (MLVA). Infect Genet Evol. 2008;8:171-81.

21. Borel N, Thoma R, Spaeni P, Weilenmann R, Teankum K, Brugnera E, et al. Chlamydia-related abortions in cattle from Graubunden, Switzerland. Vet Pathol. 2006;43:702-8. https://doi.org/10.1354/vp.43-5-702.

22. Longbottom D, Fairley S, Chapman S, Psarrou E, Vretou E, Livingstone M. Serological diagnosis of ovine enzootic abortion by enzyme-linked immunosorbent assay with a recombinant protein fragment of the polymorphic outer membrane protein POMP90 of Chlamydophila abortus. J Clin Microbiol. 2002;40:4235-43. https://doi.org/10.1128/jcm.40.11.42354243.2002.

23. Pantchev A, Sting R, Bauerfeind R, Tyczka J, Sachse K. New real-time PCR tests for species-specific detection of Chlamydophila psittaci and Chlamydophila abortus from tissue samples. Vet J. 2009;181:145-50. https:// doi.org/10.1016/j.tvj.2008.02.025.

24. OIE online mannual of diagnostic tests and vaccines for terrestrial animals 2021. Chapter 3.8.5. Enzootic abortion of ewes (Ovine Chlamydiosis). 2018. p. 1457-65.

25. Darougar S, Woodland RM, Forsey T, Cubitt S, Allami J, Jones BR. Isolation of Chlamydia from ocular infections. In: Hobson D, Holmes KK, editors. In non-gonococcal urethritis and related infections, pp. 295-298. Washington, DC: American society for microbiology; 1977.

26. World health organization. Guide to the laboratory diagnosis of trachoma. Geneva; 1975.

27. Benson G. Tandem repeats finder: a program to analyze DNA sequences. Nucleic Acids Res. 1999;27:573-80. https://doi.org/10.1093/nar/27.2.573.
28. Denamur E, Sayada C, Souriau A, Orfila J, Rodolakis A, Elion J. Restriction pattern of the major outer-membrane protein gene provides evidence for a homogeneous invasive group among ruminant isolates of Chlamydia psittaci. Microbiology. 1991;37:2525-30. https://doi.org/10.1099/ 00221287-137-11-2525.

29. Madico G, Quinn TC, Boman J, Gaydos CA. Touchdown enzyme time release-PCR for detection and identification of Chlamydia trachomatis, C. pneumoniae, and C. psittaci using the $16 \mathrm{~S}$ and 16S-23S spacer rRNA genes. J Clin Microbiol. 2000;38:1085-93 PMID:10699002.

30. Moori Bakhtiari N, Seifi MR, Ghorbanpour M, Gooraninejad S. Cloning and expression segment of the pomp90 gene Chamydophila abortus strain S2 \$3 in E. coli. Iran. Vet J. 2011:74-80 (In Persian).

31. Ebadi A, Moosakhani F, Jamshidian M. Phylogenetic analysis of Chlamydia abortus isolated from fetus aborted ewes of Alborz province. Bull Environ Pharmacol Life Sci. 2014:122-6.

32. Almeida LA, Araujo R. Highlights on molecular identification of closely related species. Infect Genet Evol. 2013;13:67-75. https://doi.org/10. 1016/j.meegid.2012.08.011.

33. Li Z, Cao X, Fu B, Chao Y, Cai J and Zhou J. Identification and characterization of Chlamydia abortus isolates from yaks in Qinghai, China. BioMed Res. Int. 2015, Article ID 658519, 6 pages. https://doi.org/10.1155/2015/ 658519.

34. Malal ME, Turkyilmaz S. Identification and genotyping of Chlamydia abortus with MLVA from ruminant abortions in the Marmara region of Turkey. Thai J Vet Med. 2021;51:169-75.

35. Siarkou VI, Vorimore F, Vicari N, Magnino S, Rodolakis A, Pannekoek Y, et al. Diversification and distribution of ruminant Chlamydia abortus clones assessed by MLST and MLVA. PLoS One. 2015;10:e0126433. https://doi. org/10.1371/journal.pone.0126433.

\section{Publisher's Note}

Springer Nature remains neutral with regard to jurisdictional claims in published maps and institutional affiliations.

Ready to submit your research? Choose BMC and benefit from:

- fast, convenient online submission

- thorough peer review by experienced researchers in your field

- rapid publication on acceptance

- support for research data, including large and complex data types

- gold Open Access which fosters wider collaboration and increased citations

- maximum visibility for your research: over $100 \mathrm{M}$ website views per year

At BMC, research is always in progress.

Learn more biomedcentral.com/submissions 